\title{
MODERNIZAÇÃO DA INSTRUMENTAÇÃO E CONTROLE DAS CALDEIRAS 8 E 9 NA CENTRAL TERMOELÉTRICA 1 DA CSN*
}

\author{
Milson de Andrade Júnior ${ }^{1}$ \\ Junior Teixeira Camargo² \\ André Luis de Oliveira ${ }^{3}$ \\ André Galdino Pontes Ferreira ${ }^{4}$
}

Resumo

A central termoelétrica número 1 (CTE\#1) da Companhia Siderúrgica Nacional possui duas caldeiras em operação denominadas 8 e 9 com capacidade total de produção de vapor de 200 Toneladas por hora. Estas caldeiras fornecem vapor para os turbo geradores e turbo sopradores da CTE\#1, além de vapor de processo para a Usina Presidente Vargas (UPV). As caldeiras entraram em operação em 1982/83 e seus sistemas de controle e instrumentação eram totalmente pneumáticos. Ao longo do tempo foi surgindo dificuldades para reposição e manutenção dos componentes pneumáticos, motivo pelo qual se iniciaram os estudos para substituição deste sistema. Em 2009 teve início um projeto para substituição do controle pneumático por um controle microprocessado feito por PLC redundante trabalhando com um supervisório scada e para substituição das malhas de instrumentação pneumática por instrumentação em rede fieldbus. A substituição completa dos componentes pneumáticos foi concluída em 2012. O novo sistema implantado trouxe diversas melhorias na performance, confiabilidade, segurança operacional e ergonomia. Este trabalho apresenta as causas que motivaram o projeto em questão, a metodologia utilizada para a sua implantação e os resultados alcançados com a aplicação de tecnologia moderna para controle e instrumentação de caldeiras.

Palavras-chave:Caldeiras; Instrumentação; Controle; Pneumático.

\section{MODERNIZATION OF INSTRUMENTATION AND CONTROL OF THE BOILER 8 AND 9 IN CSN THERMOELECTRIC PLANT 1 \\ Abstract}

The thermoelectric plant number 1 (CTE\#1) of the National Steel Company has two boilers in operation called 8 and 9 with total production capacity of 200 tons of steam per hour. These boilers provide steam for the turbo generators and turbo blowers of CTE \#1, besides process steam to the Vargas President Steelworks. The boilers were put into operation in 1982/83 and its control systems and instrumentation were completely pneumatic. Over time was appearing difficulties for replacement and maintenance of pneumatic components, reason whereby the studies began to replace this system. In 2009 began a project to replace the pneumatic control by a microprocessor control done by redundant PLC working with a supervisory SCADA and to replacement of pneumatic instrumentation loops for instrumentation with fieldbus network. The complete replacement of pneumatic components was completed in 2012. The new system deployed has brought many improvements in performance, reliability, operational safety and ergonomics. This work presents the causes that motivated the project in question, the methodology used for its implementation and the results achieved with the application of modern technology for boilers control and instrumentation.

Keywords: Boiler; Instrumentation; Control; Pneumatic.

1 Engenharia Eletrônica, Engenheiro de Manutenção, Gerência de Geração de Energéticos, Companhia Siderúrgica Nacional (CSN), Volta Redonda, Rio de Janeiro, Brasil.

2 Técnico em Instrumentação, Inspetor de Manutenção, Gerência de Geração de Energéticos, Companhia Siderúrgica Nacional, Volta Redonda, Rio de Janeiro, Brasil.

3 Engenharia Eletrônica, Engenheiro de Manutenção, Gerência de Geração de Energéticos, Companhia Siderúrgica Nacional, Volta Redonda, Rio de Janeiro, Brasil.

4 Técnico em Instrumentação, Supervisor de Manutenção Elétrica, Gerência de Geração de Energéticos, Companhia Siderúrgica Nacional, Volta Redonda, Rio de Janeiro, Brasil.

\footnotetext{
* Contribuição técnica ao $35^{\circ}$ Seminário de Balanços Energéticos Globais e Utilidades e $29^{\circ}$ Encontro de Produtores e Consumidores de Gases Industriais, 13 a 15 de agosto de 2014, São Paulo, SP, Brasil.
} 


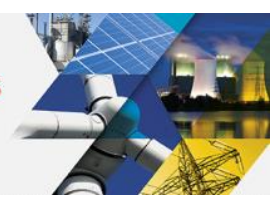

\section{INTRODUÇÃO}

A Central Termoelétrica 1 (CTE\#1) da CSN desempenha um importante papel nas utilidades da Usina Presidente Vargas (UPV), sendo responsável pela alimentação de parte das cargas de $50 \mathrm{~Hz}$, ar soprado de emergência para os alto-fornos e contribuindo com o fornecimento de vapor de processo para diversas áreas.

O vapor da CTE\#1 é produzido em duas caldeiras de alta pressão do tipo aquatubulares com capacidade de produção de $200 \mathrm{~T} / \mathrm{h}$ de vapor. Estas caldeiras são denominadas como CAP's 8 e 9 . O vapor produzido nas caldeiras tem a função de transmitir movimento aos geradores de energia elétrica e sopradores de ar através de turbinas a vapor (figura 1).

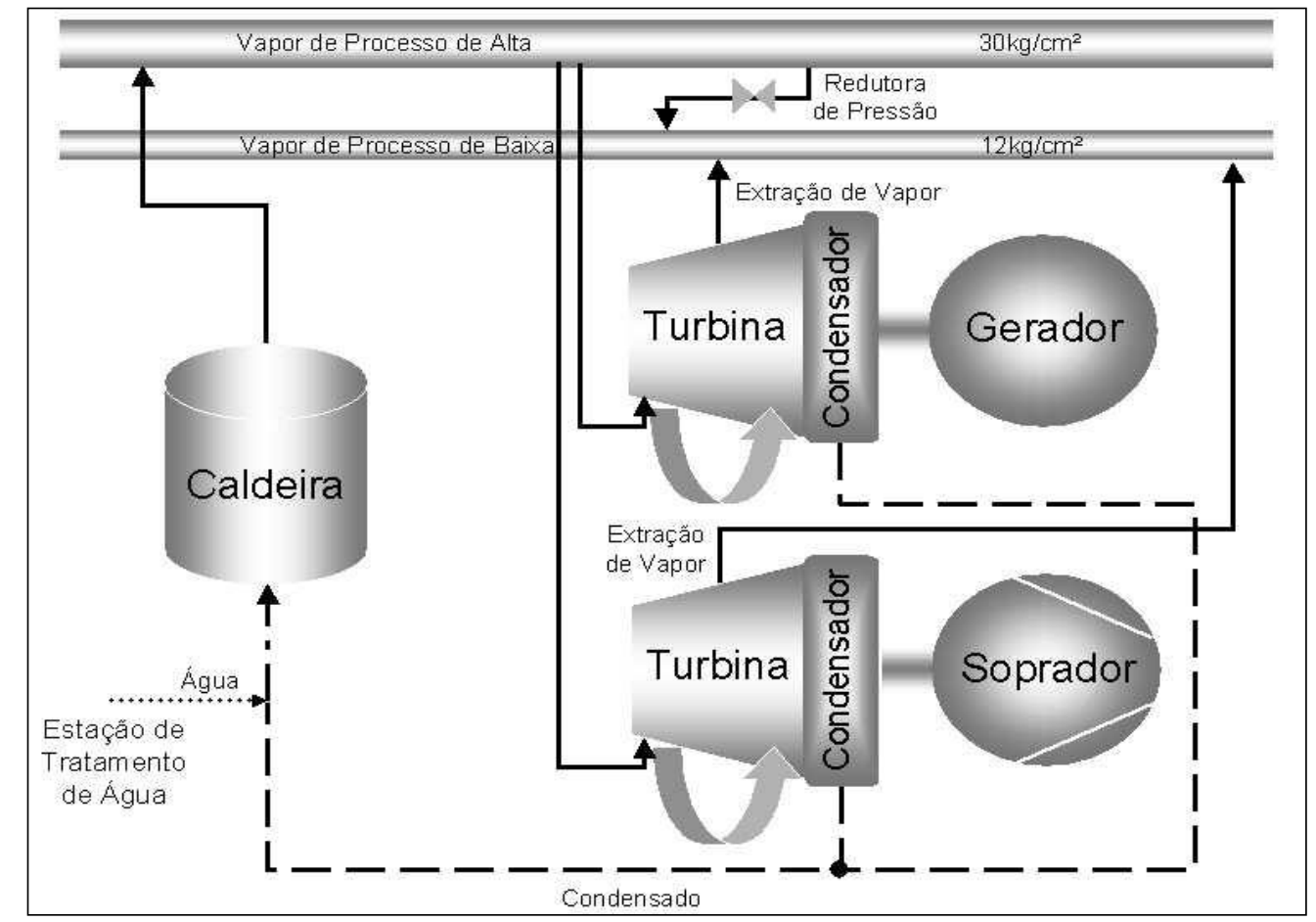

Figura 1 - Fluxograma de vapor na CTE\#1

O vapor de processo é utilizado em diversas áreas da CSN, tanto o vapor de alta (30 $\mathrm{Kgf} / \mathrm{cm} 2)$ quanto o vapor de baixa $(12 \mathrm{Kgf} / \mathrm{cm} 2)$. Dentre elas podemos citar PHOSAN, Forno RH, Zincagem, Carboquímico, Cozinha Industrial, entre outros.

\subsection{Características das Caldeiras 8 e 9}

As caldeiras 8 e 9 possuem 4 queimadores. Em cada queimador é possível queimar até 4 combustíveis diferentes: gás de alto forno, gás de coqueria, gás natural e óleo BPF. O gás de coqueria funciona como um gás piloto, o qual tem a função de estabilizar a chama de cada queimador.

O principal combustível utilizado nas caldeiras para produção de vapor é o Gás de Alto Forno, o qual é proveniente do processo siderúrgico e está disponível em grande volume e com baixo custo.

As caldeiras possuem as seguintes características técnicas:

- Fabricante: CBC

- Tipo: Aquotubular VU-60

- Ano de fabricação: 1980

\footnotetext{
* Contribuição técnica ao $35^{\circ}$ Seminário de Balanços Energéticos Globais e Utilidades e $29^{\circ}$ Encontro de Produtores e Consumidores de Gases Industriais, 13 a 15 de agosto de 2014, São Paulo, SP, Brasil.
} 


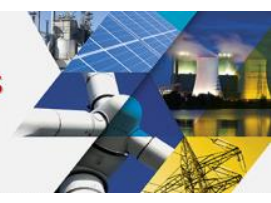

- Pressão máxima de trabalho permitida: $38 \mathrm{~kg} / \mathrm{cm}^{2}$

- Pressão de prova: $57 \mathrm{~kg} / \mathrm{cm}^{2}$

- Superfície de aquecimento: $2844 \mathrm{~m}^{2}$

- Capacidade de produção: $100.000 \mathrm{~kg} / \mathrm{h}$

- Temperatura do vapor superaquecido: $385^{\circ} \mathrm{C}$

\subsection{Histórico}

A caldeira 8 entrou em operação em 1983 e a caldeira 9 em 1982. Desde então as caldeiras estavam operando sem nenhum projeto significativo de melhoria. $O$ controle e as proteções das caldeiras eram feitos por instrumentos e equipamentos pneumáticos, os quais se tornavam difíceis para manutenção e reposição com o passar dos anos. A operação era feita por um grande painel (figura 2) com diversos controladores, indicadores e sinalizadores, os quais não eram nada ergonômicos. Os registros de dados eram feitos por cartas gráficas e/ou anotados a mão pelos operadores. Porém, poucas variáveis eram monitoradas e não havia histórico de alarmes e/ou eventos, o que fazia com que muitas ocorrências não pudessem ser apuradas com precisão. As proteções operacionais das caldeiras não eram totalmente confiáveis, pois o sistema de intertravamento existente podia ser burlado através da colocação de calços em relés impedindo a sua atuação.

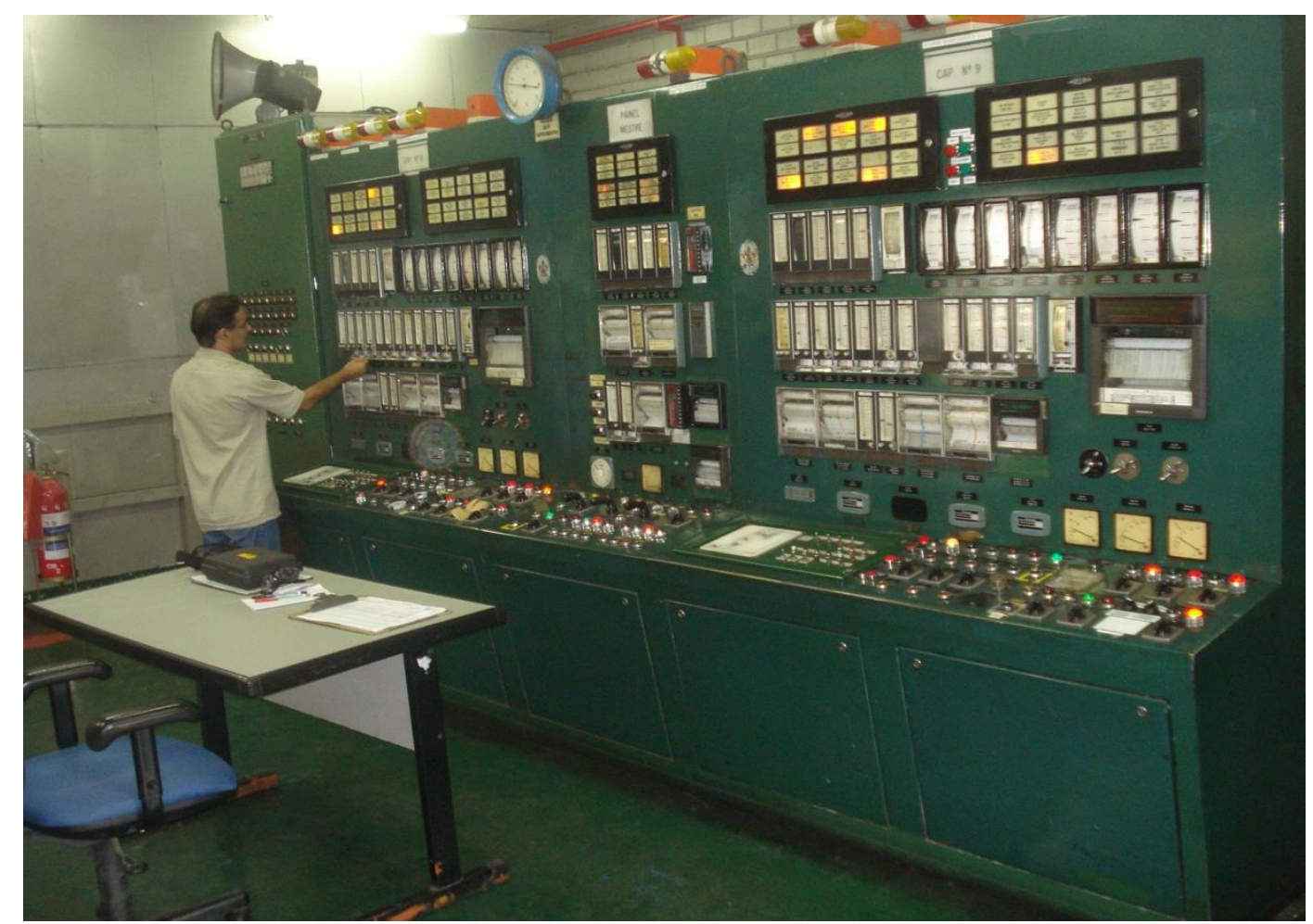

Figura 2 - Painel de Operação antigo

Os CCM's de 460V (figura 3) que alimentavam os equipamentos auxiliares das caldeiras estavam em desacordo com a nova NR-10 colocando em risco operadores e técnicos de manutenção.

\footnotetext{
* Contribuição técnica ao $35^{\circ}$ Seminário de Balanços Energéticos Globais e Utilidades e $29^{\circ}$ Encontro de Produtores e Consumidores de Gases Industriais, 13 a 15 de agosto de 2014, São Paulo, SP, Brasil.
} 


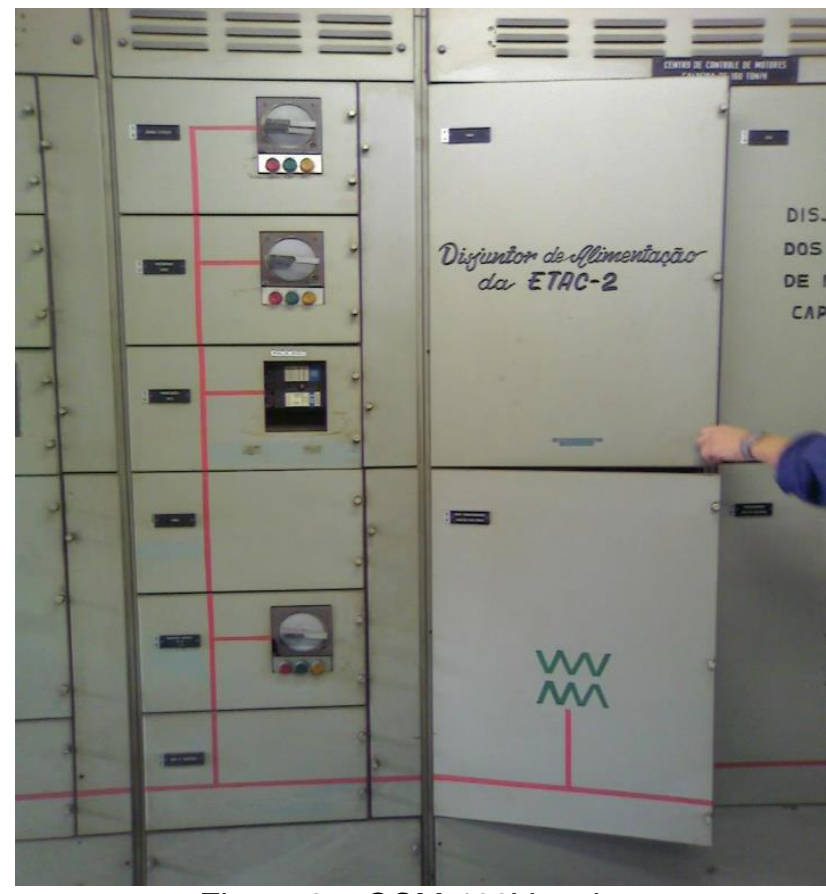

Figura 3 - CCM 460V antigo

\subsection{Objetivo}

Elaborou-se um projeto de automação para as caldeiras 8 e 9 baseado nos seguintes pilares:

a) Continuidade operacional: Para que as caldeiras continuassem desempenhando seu papel operacional sem riscos de interferências no processo era necessário substituir todo o controle e instrumentação pneumáticos.

b) Confiabilidade operacional: Para que a CTE\#1 continuasse desempenhando seu papel operacional era necessário a implantação de um modelo de automação e instrumentação confiável, seguro e com redundâncias.

c) Flexibilidade: Era necessário implementar um novo sistema que permitisse melhorias e atualizações tecnológicas com o passar dos anos.

d) Segurança e saúde ocupacional: Os equipamentos novos deveriam ser ergonômicos e seguros de forma a garantir a integridade física dos operadores e profissionais de manutenção.

\section{MATERIAIS E MÉTODOS}

Em meados de 2009 foi iniciado o projeto para substituição de todo controle e instrumentação das caldeiras 8 e 9 e painel mestre (sistema comum), além da substituição do CCM de 460V. O projeto passou por duas paralisações para aditivos contratuais sendo concluído em 2012.

A caldeira 8 foi automatizada em abril de 2011e para tal foi necessário uma parada de 30 dias do equipamento. A caldeira 9 foi automatizada em julho de 2012 com uma parada também de 30 dias. Dentro desse período foi necessário uma parada total (caldeiras 8 e 9) por 5 dias para automação do sistema comum (painel mestre). Dentre os serviços executados pode-se citar resumidamente os seguintes:

- Substituição de todas as malhas de controle pneumáticas dos três sistemas (caldeira 8, caldeira 9 e painel mestre) por um PLC modelo stardom da Yokogawa, sendo um PLC reduntante para cada sistema;

\footnotetext{
* Contribuição técnica ao $35^{\circ}$ Seminário de Balanços Energéticos Globais e Utilidades e $29^{\circ}$ Encontro de Produtores e Consumidores de Gases Industriais, 13 a 15 de agosto de 2014, São Paulo, SP, Brasil.
} 
- Substituição de todos os instrumentos pneumáticos por instrumentos em rede Fieldbus;

- Substituição do CCM de 460V que alimenta as cargas auxiliares das caldeiras por um CCM adequado a NR-10;

- Instalação de dois sistemas supervisórios para operação das caldeiras com banco de dados para armazenamento de informações;

- Substituição do sistema de ignição e detecção de chama dos queimadores;

- Instalação de dois no-breaks para alimentação estabilizada e de emergência para todo sistema de controle e instrumentação;

- Substituição de todas as válvulas de controle.

- Instalação de analisadores de CO2 e O2.

\subsection{PLC}

O PLC utilizado no controle do processo das Caldeiras 8 e 9 é o Stardom da Yokogawa, o qual é um PLC híbrido que agrega funções de SDCD e PLC. Ele é conectado em rede FieldBus com os instrumentos de campo e conectado em rede ethernet com o sistema SCADA (Sistema de Controle e Aquisição de Dados).

Foi utilizado sistema com Fonte e CPU redundantes e Módulos de Repetição SB Bus simples para a aplicação das Caldeiras 8 e 9.

A comunicação entre as CPU's é feita através de rede padrão Ethernet (HSE - High Speed Ethernet) em 100 Mbits/s.

A comunicação com os instrumentos de campo é realizada através do protocolo Foundation Fieldbus.

Na figura 4 é possível ver a arquitetura geral do novo sistema de automação.

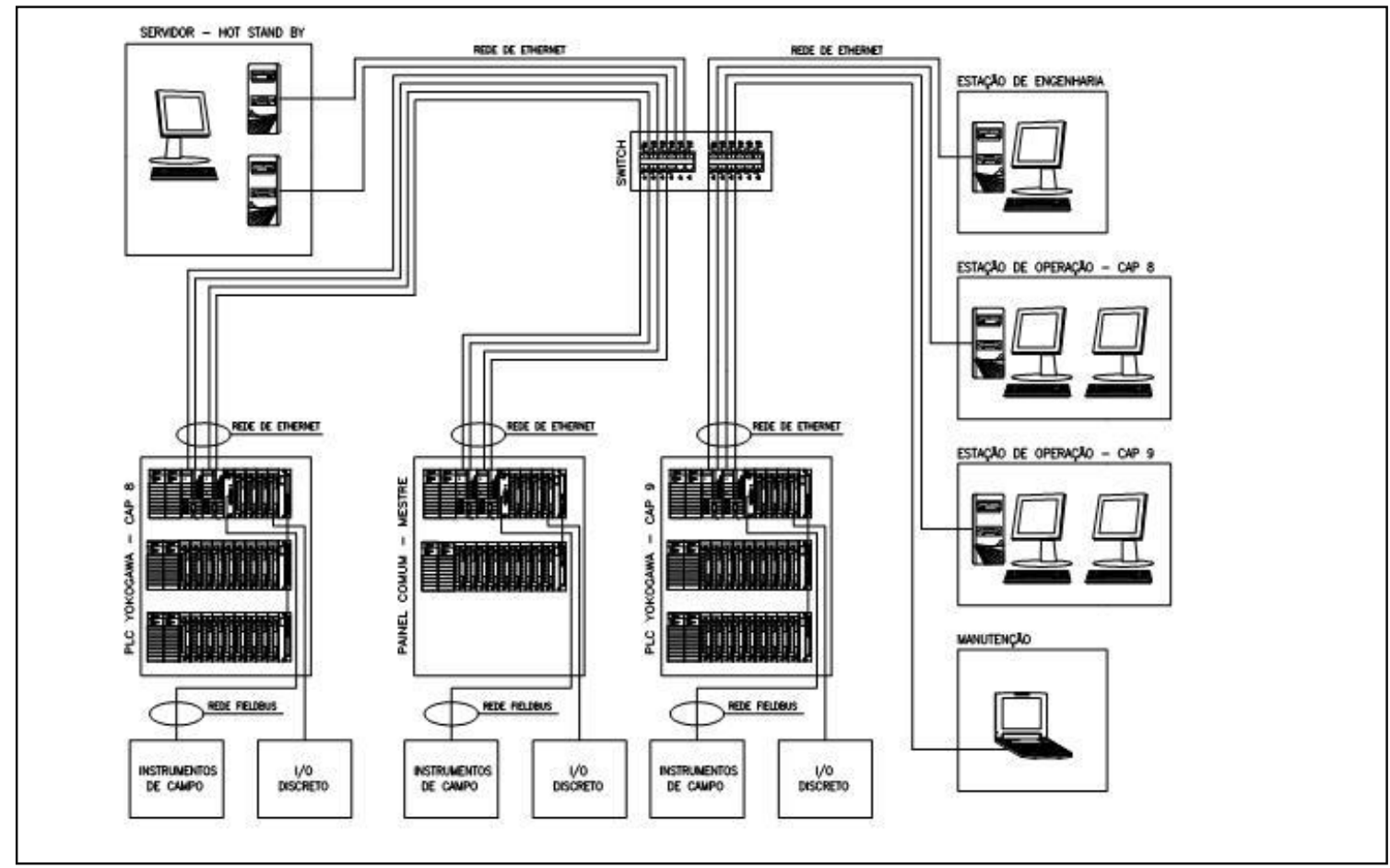

Figura 4 - Arquitetura automação

* Contribuição técnica ao $35^{\circ}$ Seminário de Balanços Energéticos Globais e Utilidades e $29^{\circ}$ Encontro de Produtores e Consumidores de Gases Industriais, 13 a 15 de agosto de 2014, São Paulo, SP, Brasil. 


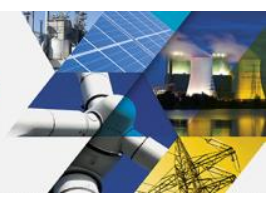

Foi desenvolvida a mesma lógica de controle na Caldeira 8 e na Caldeira 9 a fim de manter o princípio de funcionamento do projeto original. As proteções e intertravamentos das caldeiras foram mantidas conforme o projeto.

\subsection{Instrumentação}

A rede utilizada para fazer a comunicação entre os equipamentos de campo e o controlador (PLC) foi a Foundation Fieldbus.

A opção por utilizar instrumentação Filedbus no projeto foi em virtude das seguintes vantagens observadas:

- Controle distribuído: Parte do controle pode ser realizado nos próprios equipamentos de campo. Com isso há uma redução de processamento da CPU do PLC, pois a mesma não necessita executar e controlar todas as malhas, podendo usar sua capacidade para outros controles

- Otimização de cabeamento: Redução no custo de cabeamento pois a comunicação da malha é realizada através do próprio cabo da Rede Foundation Fieldbus.

- Simplicação de documentação: Redução do trabalho na elaboração da documentação, fluxogramas e diagramas devido à simplificação do sistema de cabeamento.

- Tecnologia atualizada: Instrumentação de ponta com diversos recursos.

\subsection{Sistema Scada}

Para supervisão, controle e aquisição de dados do processo foi utilizado o Elipse E3 versão 3.0 da Elipse software. O software é composto por um sistema aberto que pode sofrer acréscimos de funcionalidades ao longo do tempo permitindo supervisionar outros processos proporcionando um melhor aproveitamento do mesmo.

O software de supervisão tem as seguintes características:

- Aquisição de dados de tempo real;

- Dados históricos para manutenção;

- Interface com o operador;

- Facilidades para configuração;

- Ferramentas para acesso a outros sistemas.

O software de supervisão define os níveis de operação conforme segue:

- Visualização - permite somente visualização e não é permitida nenhuma operação;

- Operação - permite todo nível operacional com acesso do operador a todas as telas e funções operacionais tais como: trocar os modos de operação, ligar e desligar, abrir e fechar, trocar set-point, reconhecimento de alarmes, trocar modo de operação dos controladores e etc.;

- Engenharia - neste nível, o acesso é total a todas as funções do sistema.

A Comunicação com o PLC é via rede local, utilizando driver de comunicação do supervisório com o PLC, com comunicação via Ethernet TPC/IP. A atualização dos dados é feita a cada 1 segundo.

Os dados para registro de históricos tais como: gráficos de tendências, eventos operacionais e alarmes foram configurados de acordo com a necessidade do processo e ficam disponíveis no sistema por 30 dias para consulta. Foi utilizado o banco de dados Oracle $11 \mathrm{~g}$ para armazenamento das informações.

* Contribuição técnica ao $35^{\circ}$ Seminário de Balanços Energéticos Globais e Utilidades e $29^{\circ}$ Encontro de Produtores e Consumidores de Gases Industriais, 13 a 15 de agosto de 2014, São Paulo, SP, Brasil. 


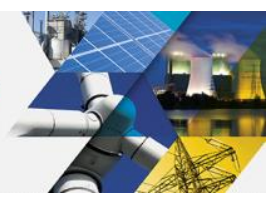

O sistema possui dois servidores e duas estações de operação. Para cada estação de operação foi previsto dois monitores. O sistema ainda possui uma máquina exclusiva para manutenção onde está instalado o software PRM da Yokogawa que é um gerenciador de ativos com diversas funcionalidades para a manutenção.

\subsection{CCM (Centro de Controle de Motores)}

O CCM instalado possui duas alimentações distintas (uma para cada caldeira independente) e um disjuntor TIE (interligação) entre as alimentações para caso seja necessário energizar todo o CCM por apenas uma alimentação de entrada. Os cubículos de entrada têm multimedidores com protocolo Ethernet Modbus. As gavetas deste novo CCM possuem pontos de $\mathrm{I} / \mathrm{O}$ e disjuntores monitorados pelo PLC e visualizados pelo Supervisório para indicação de status da gaveta.

\subsection{Sistema de Ignição e Detecção de Chamas}

Os queimadores das caldeiras 8 e 9 possuem um sistema de bicos independentes que permitem a queima de quatro diferentes tipos de combustíveis: Gás de Alto Forno, Gás Natural, Óleo combustível e Gás de Coqueria (gás piloto). 0 acendimento de um queimador é feito através de ignitores de gás de coqueria. Após detectar chama no queimador é liberado a abertura do piloto de gás de coqueria, o qual tem a função de estabilizar a chama. Somente após isso, é possível colocar outros combustíveis para queimar no queimador.

A detecção da chama piloto do gás é feita através de um dispositivo eletrônico (Sensor de Chama) que possui um eletrodo introduzido na variável medida. Quando o dispositivo sensor detecta a falta de chama em um queimador, automaticamente as válvulas são fechadas e o queimador entra em "TRIP".

Existem dois painéis próximos aos queimadores, que possibilitam ao operador fazer o comando de abertura e fechamento das válvulas através do acionamento pares de botoeiras.

Caso ocorra um trip de um queimador, as válvulas correspondentes ao mesmo fecham e uma sinalização luminosa localizada nos painéis de acionamento das válvulas acende. $\mathrm{Na}$ sala de operação um alarme sonoro é acionado e o supervisório exibe um alarme de queimador em "TRIP".

Caso ocorra um trip da caldeira por atuação de alguma proteção, todas as válvulas são fechadas, as sinalizações luminosas dos quatro queimadores localizadas nos painéis de acionamento das válvulas acendem indicando o trip. Na sala de operação é acionado um alarme sonoro e o supervisório indica alarme de caldeira em "TRIP".

\section{RESULTADOS E DISCUSSÃO}

A sala de operação foi totalmente reformada e climatizada tornando o ambiente de operação mais confortável. A operação das caldeiras passou a ser feita em uma estação com 5 monitores (figura 5).

\footnotetext{
* Contribuição técnica ao $35^{\circ}$ Seminário de Balanços Energéticos Globais e Utilidades e $29^{\circ}$ Encontro de Produtores e Consumidores de Gases Industriais, 13 a 15 de agosto de 2014, São Paulo, SP, Brasil.
} 

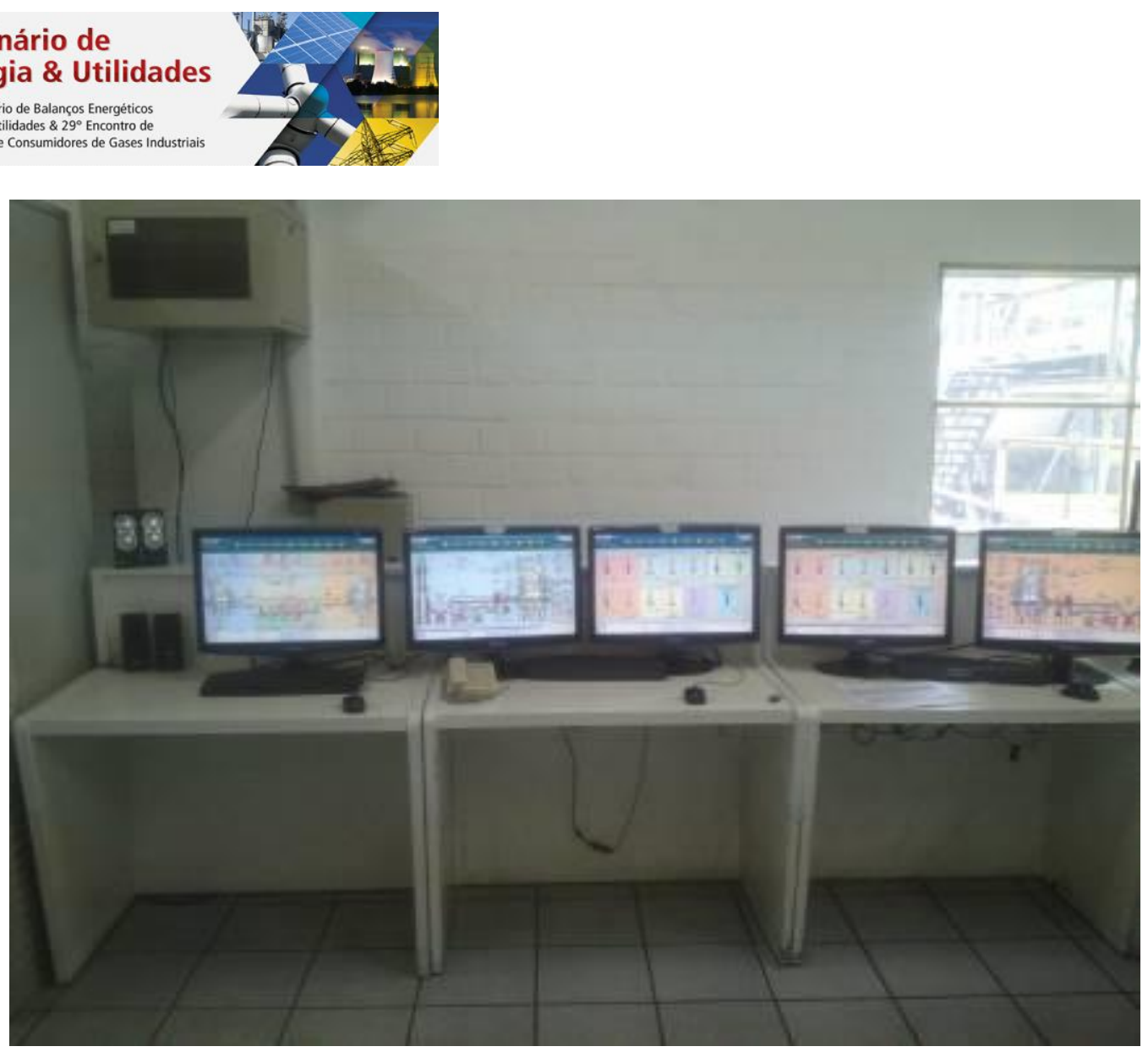

Figura 5 - Monitores de operação

As telas do supervisório foram desenvolvidas de forma a otimizar a operação dos equipamentos, tornando sua operação fácil e intuitiva. Na figura 6 pode-se observar a tela de operação principal da caldeira 9. Foi desenvolvido uma tela para cada sistema. Em cada tela é possível verificar o status dos principais equipamentos referentes ao respectivo sistema e ter uma visão macro da condição operacional de todo processo.

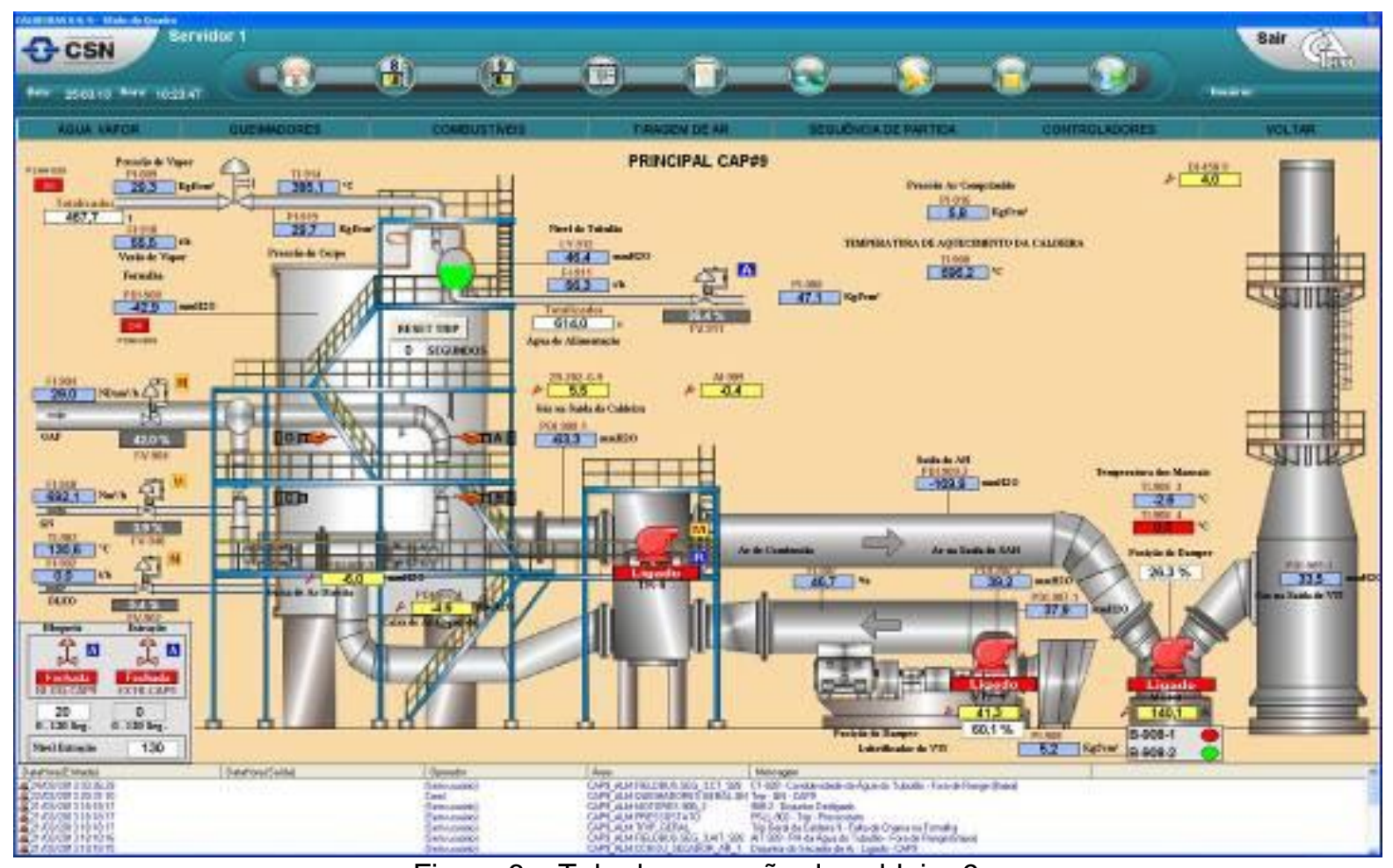

Figura 6 - Tela de operação da caldeira 9

* Contribuição técnica ao $35^{\circ}$ Seminário de Balanços Energéticos Globais e Utilidades e $29^{\circ}$ Encontro de Produtores e Consumidores de Gases Industriais, 13 a 15 de agosto de 2014, São Paulo, SP, Brasil. 


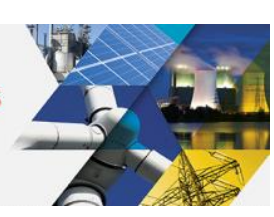

Foi desenvolvido uma lista de histórico de eventos e alarmes que possibilitam a pesquisa de defeitos e a apuração de ocorrências de maneira fácil e objetiva listando os acontecimentos cronologicamente com atualização de 1 segundo. Todas as informações ficam armazenadas em um banco de dados para consulta por um período de 30 dias. Na figura 7 pode-se verificar a tela de histórico de eventos e na figura 8 pode-se verificar a tela de alarmes.

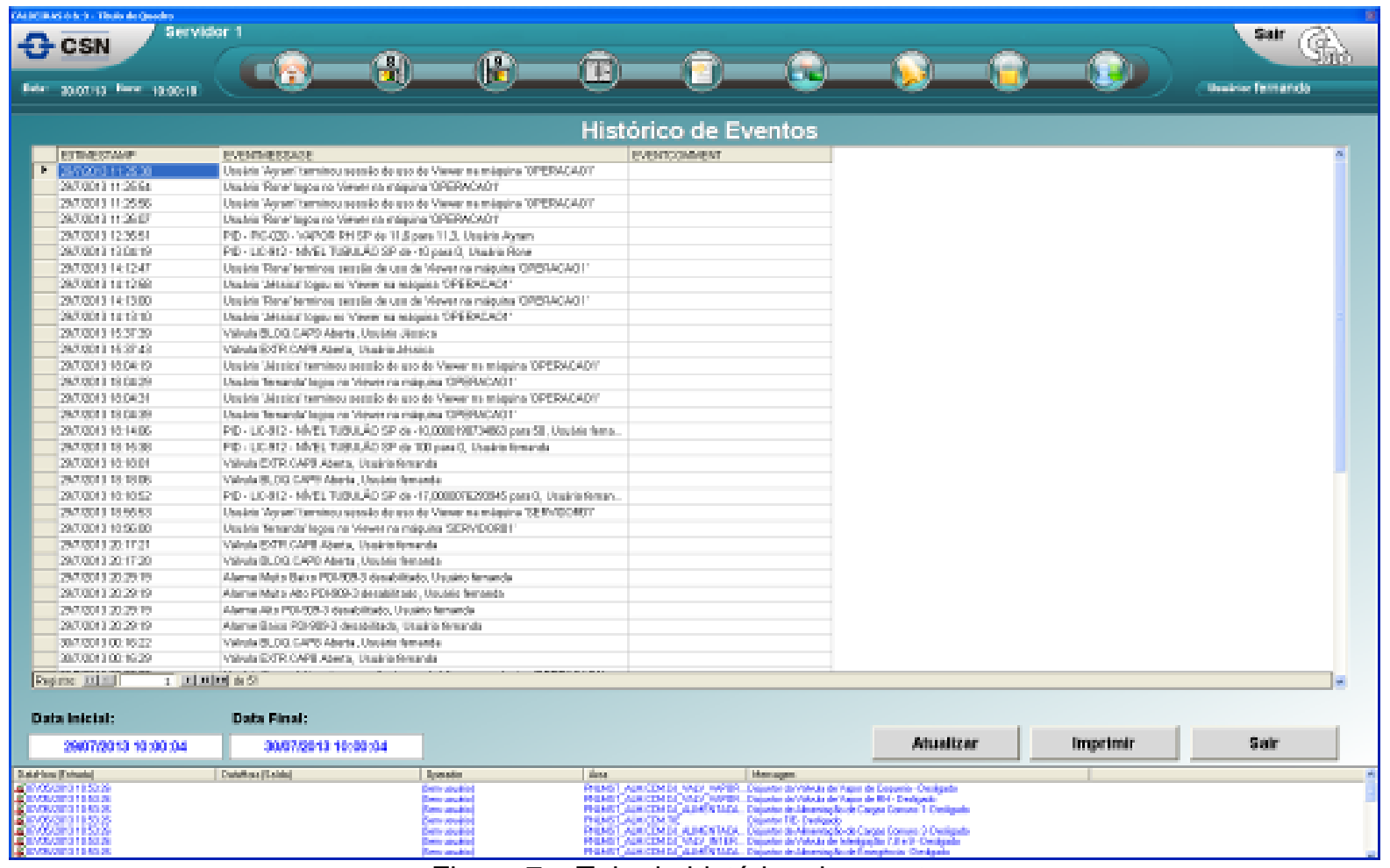

Figura 7 - Tela de histórico de eventos

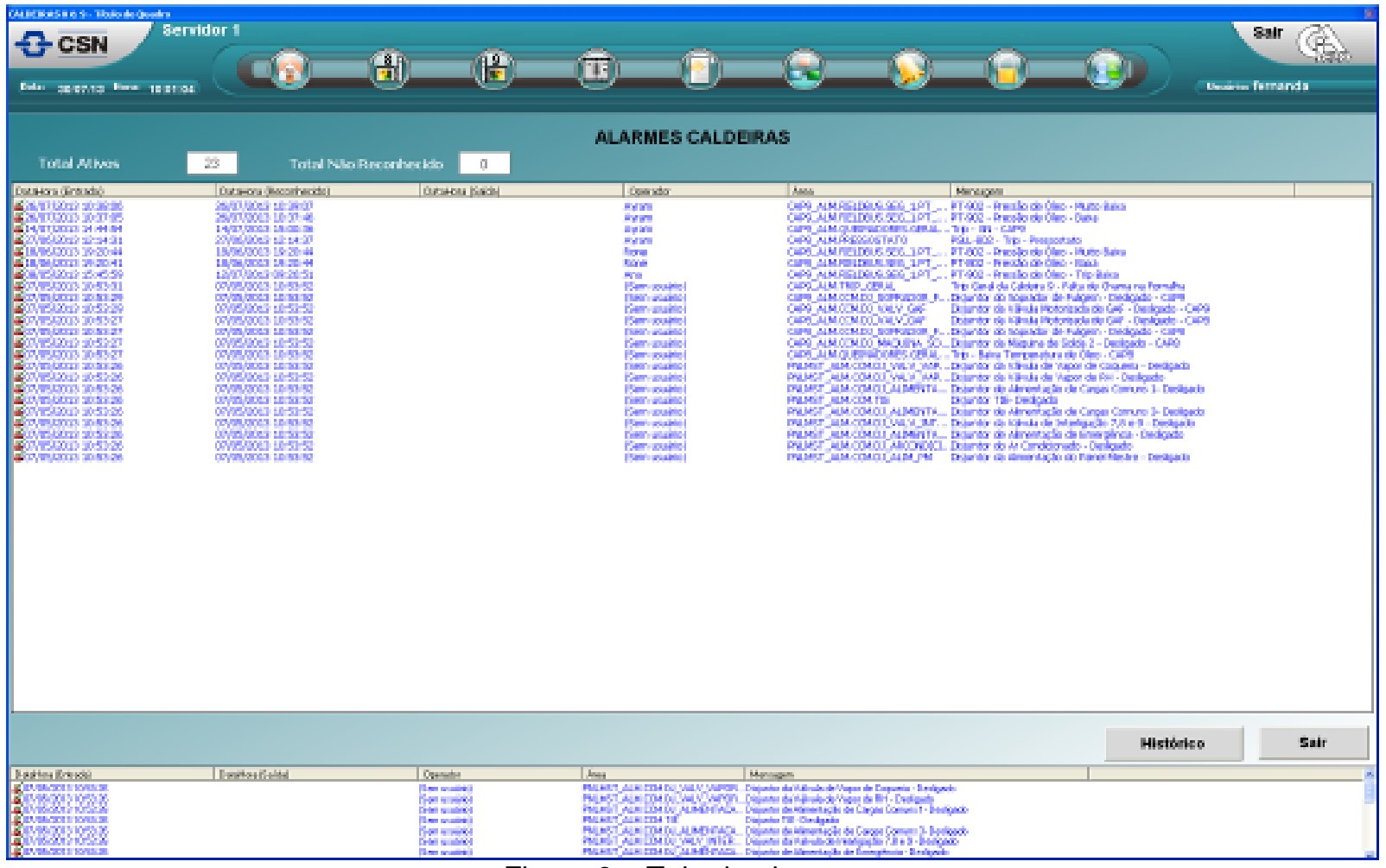

Figura 8 - Tela de alarmes

* Contribuição técnica ao $35^{\circ}$ Seminário de Balanços Energéticos Globais e Utilidades e $29^{\circ}$ Encontro de Produtores e Consumidores de Gases Industriais, 13 a 15 de agosto de 2014, São Paulo, SP, Brasil. 

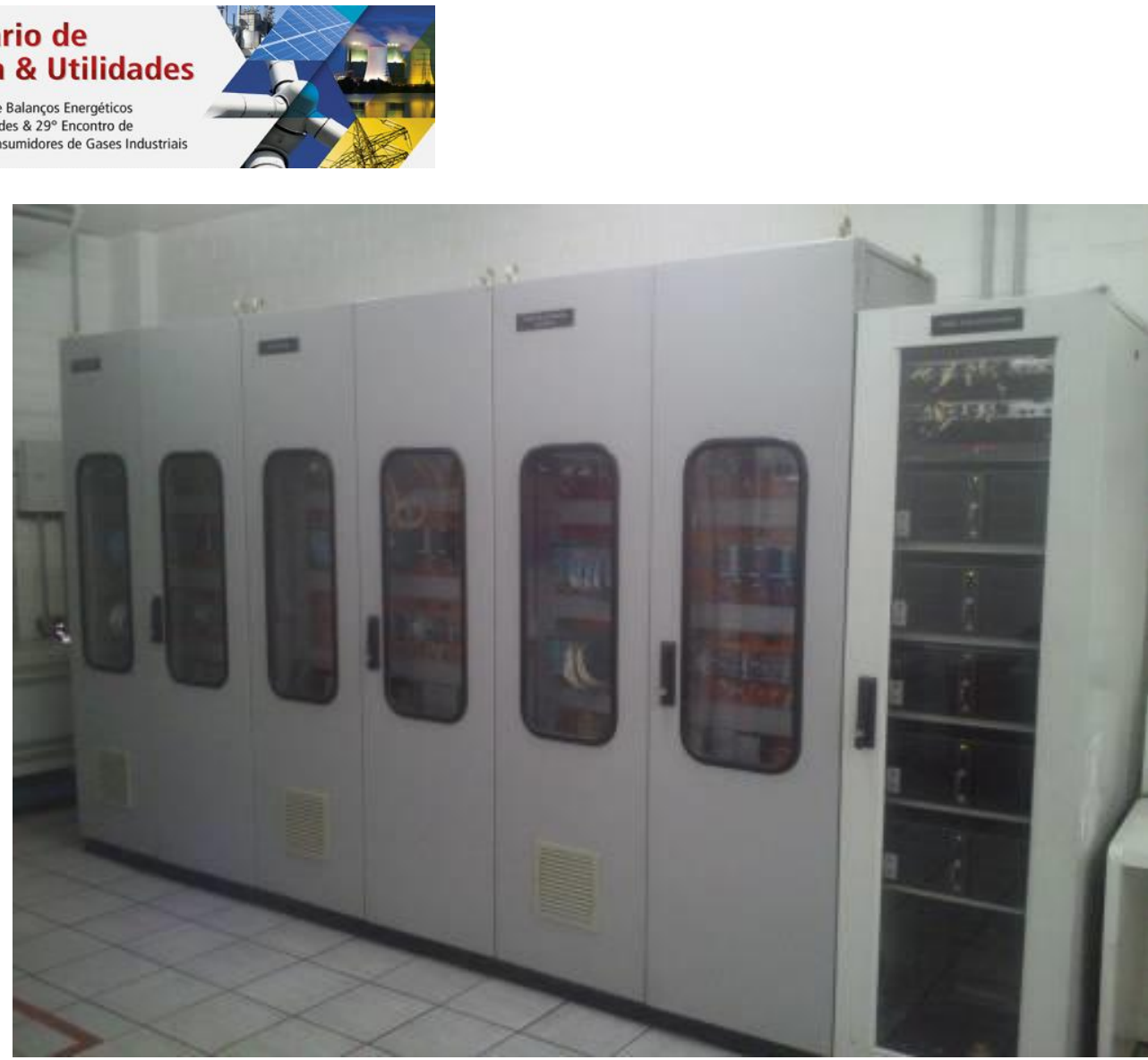

Figura 10 - Painel do PLC e rack dos servidores.

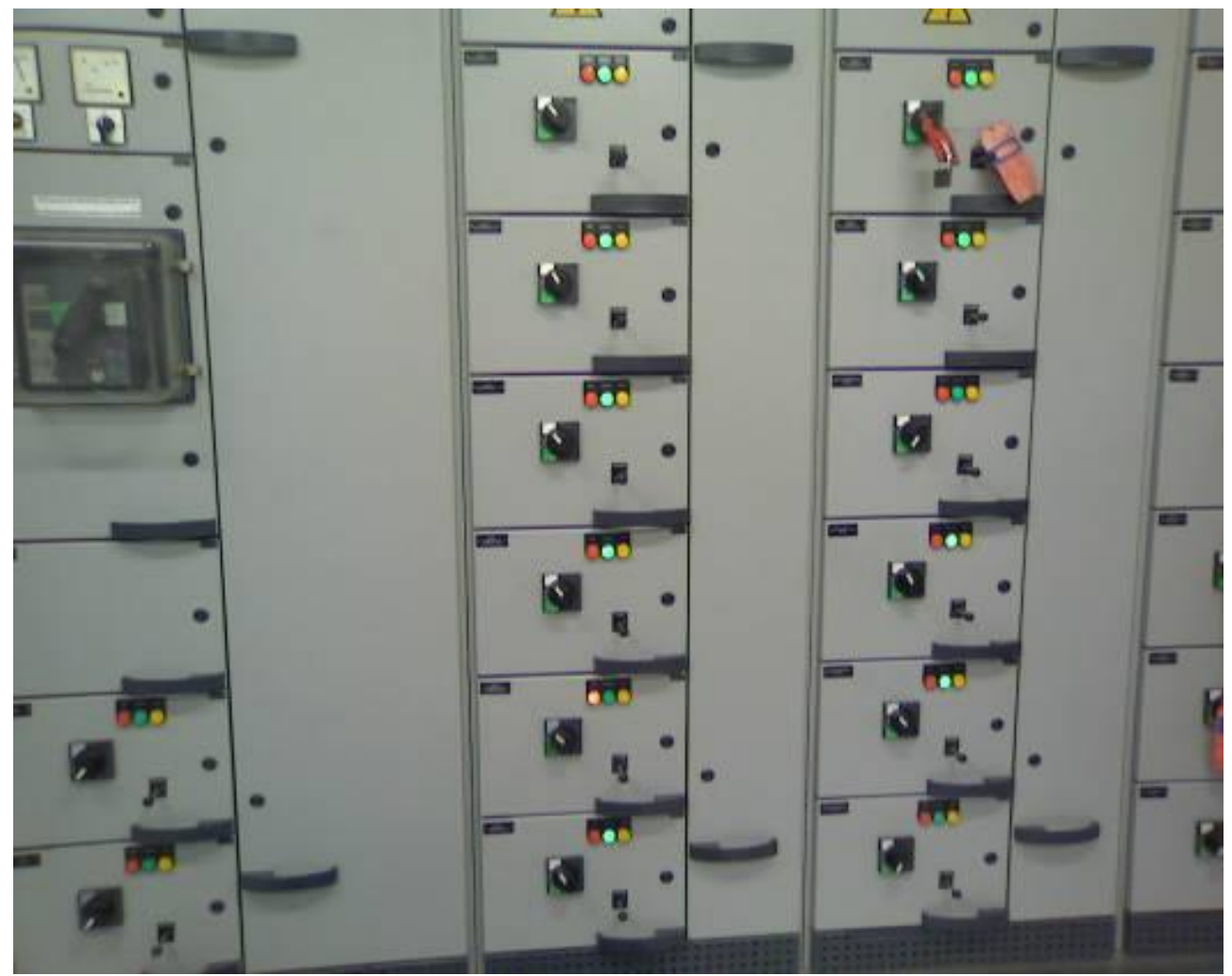

Figura 11 - CCM 460V

* Contribuição técnica ao $35^{\circ}$ Seminário de Balanços Energéticos Globais e Utilidades e $29^{\circ}$ Encontro de Produtores e Consumidores de Gases Industriais, 13 a 15 de agosto de 2014, São Paulo, SP, Brasil. 


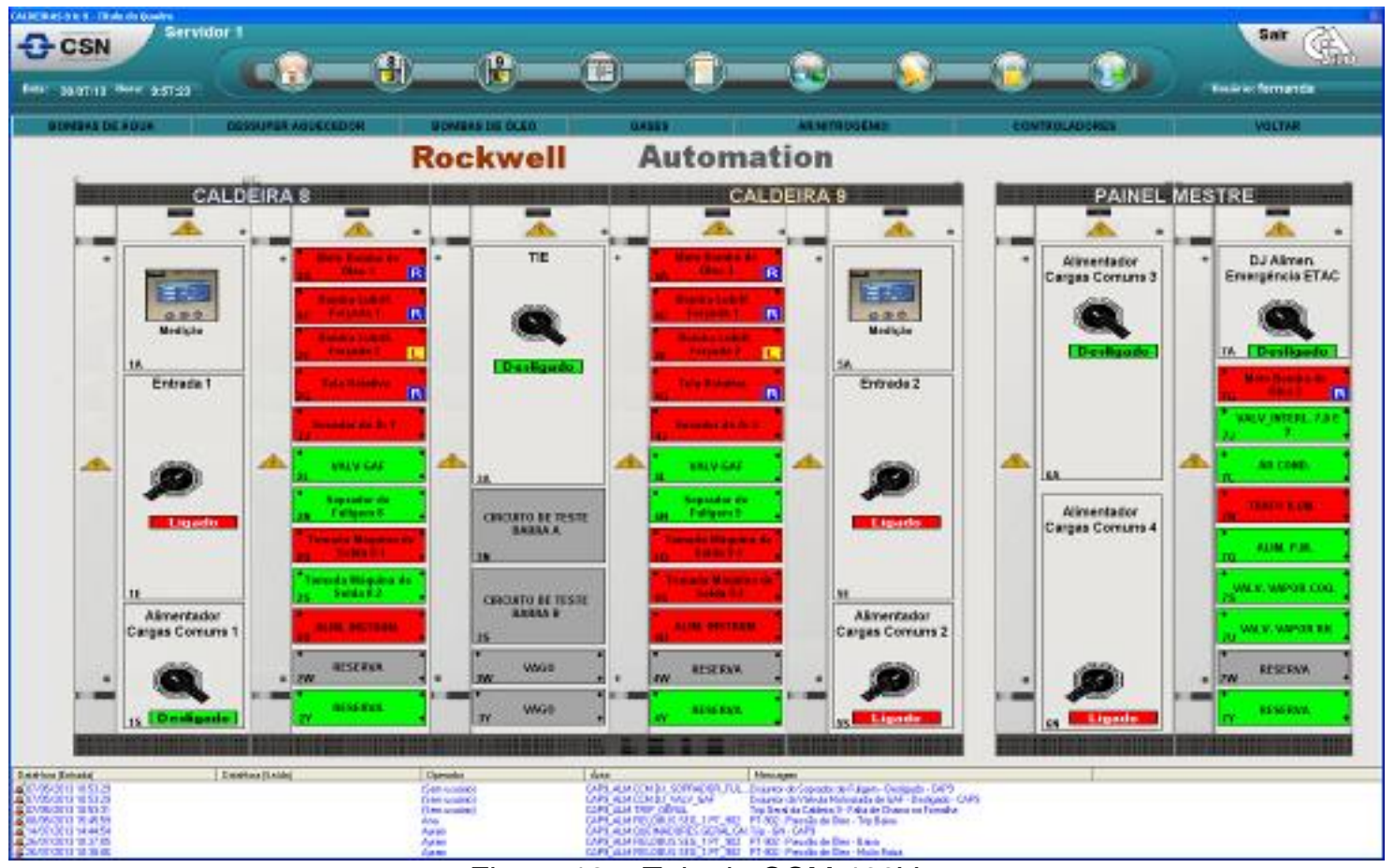

Figura 12 - Tela do CCM 460V

Com a implementação do projeto de automação das caldeiras 8 e 9 , o acompanhamento operacional das caldeiras passou a contar com uma ferramenta de maior precisão, confiabilidade operacional e com atualização instantânea dos valores trazendo maior conforto operacional. $O$ banco de dados desenvolvido possibilitou a análise de ocorrências com maior agilidade reduzindo o tempo de parada.

A substituição de equipamentos obsoletos reduziu a necessidade de manutenção constante, o que era necessário com as cartas gráficas e equipamentos pneumáticos.

A satisfação operacional foi reconhecida, pois o projeto remodelou toda a operação dos equipamentos focando em ergonomia e otimizando a sua operação com a aplicação de tecnologia moderna para controle de caldeiras com mais de 30 anos de operação.

\subsection{Aumento de eficiência}

O ganho de eficiência pode ser comprovado através da relação combustível/vapor. Pode-se verificar no gráfico da figura 13 que no ano de 2010 (ano anterior ao inicio de implantação do projeto) e no ano de 2011 (início da implantação do projeto) a quantidade de Gcal de combustível necessário para produzir uma tonelada de vapor era de 0,92 . Nos anos posteriores essa relação foi caindo até atingir uma média de 0,82 no ano de 2013 (ano após a conclusão do projeto). Percebe-se assim que hoje as caldeiras consomem menos combustível comparado com o período anterior a automação para produzir a mesma quantidade de vapor, comprovando o ganho de eficiência obtido.

\footnotetext{
* Contribuição técnica ao $35^{\circ}$ Seminário de Balanços Energéticos Globais e Utilidades e $29^{\circ}$ Encontro de Produtores e Consumidores de Gases Industriais, 13 a 15 de agosto de 2014, São Paulo, SP, Brasil.
} 


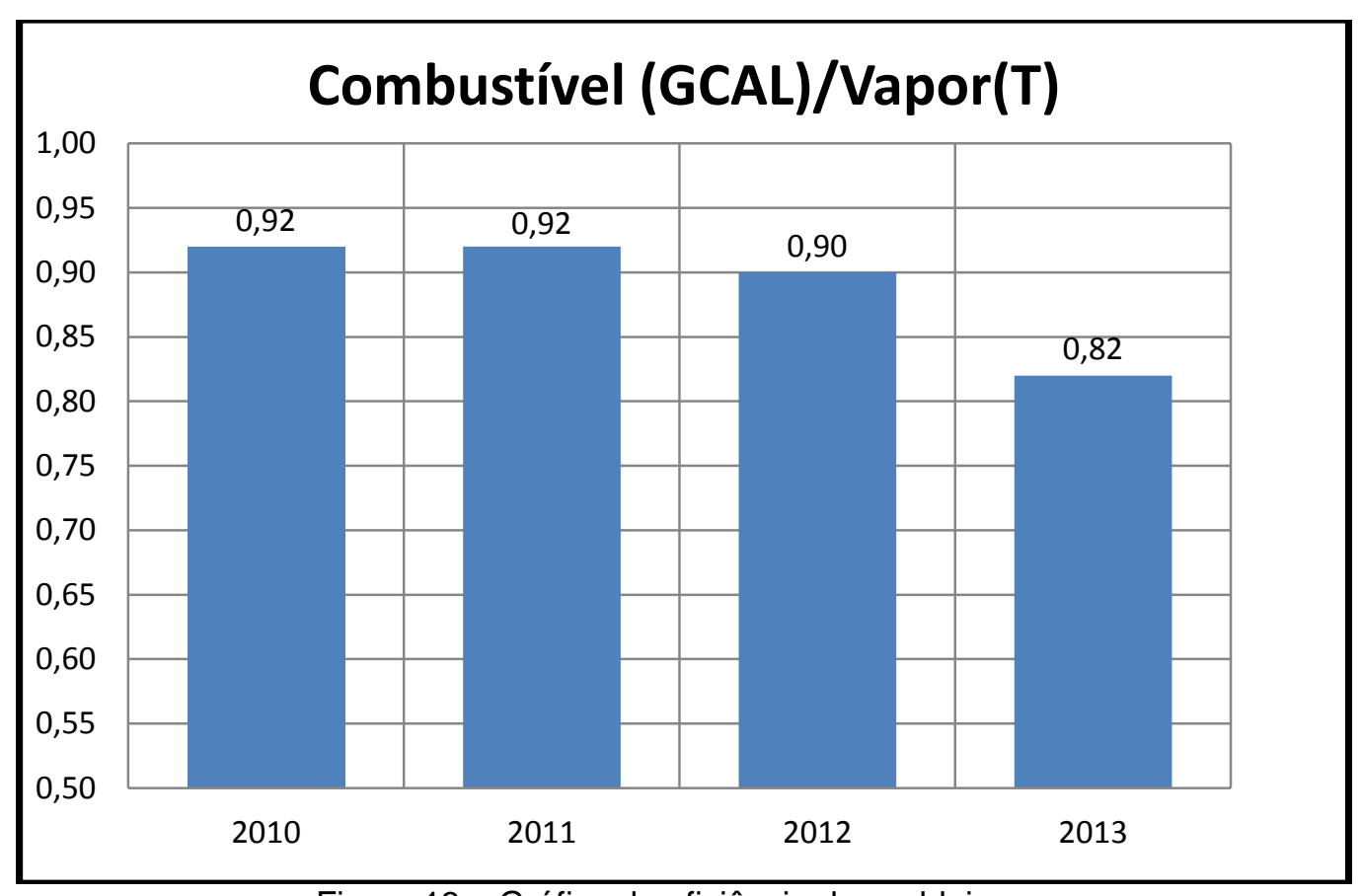

Figura 13 - Gráfico de eficiência das caldeiras

O ganho de eficiência pode ser explicado por dois fatores principais:

- Controle de nível: a resposta mais rápida do controle microprocessado possibilitou um controle de nível mais estável e eficiente.

- Analisadores de CO e O2: a instalação de analisadores na saída dos gases queimados da caldeira possibilitou um melhor ajuste da relação ar/combustão.

\subsection{Balanço financeiro}

Foi investido o total de $\mathrm{R} \$ 5.313 .000,00$ na automação das duas caldeiras. O investimento feito garantiu a continuidade operacional das caldeiras e possibilitou a implantação de diversas melhorias no processo. Percebe-se que houve significativo ganho na eficiência das caldeiras devido a menor quantidade de combustível necessário para produzir a mesma quantidade de vapor que era produzido anteriormente.

Com a redução da relação Gcal/tonelada de vapor de 0,92 para 0,82 passou-se a utilizar menos $0,10 \mathrm{Gcal}$ para produzir uma tonelada de vapor. Transformando esse valor de energia em volume de combustível chegamos aos valores abaixo:

- Para se produzir 0,10 Gcal através da queima do gás de alto forno é necessário 0,128 dam $^{3}$ de gás de alto forno.

- Para se produzir 0,10 Gcal através da queima do gás de coqueria é necessário 0,025 dam $^{3}$ de gás de coqueria.

- Para se produzir 0,10 Gcal através da queima de óleo BPF é necessário 0,010 T de óleo BPF.

- Para se produzir 0,10 Gcal através da queima do gás natural é necessário 0,012 dam $^{3}$ de gás de natural.

Os valores de referência da quantidade de energia produzida por cada combustível pode ser verificada na tabela 1. 


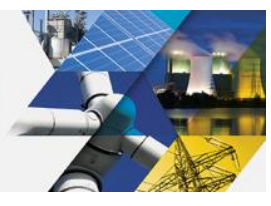

Tabela 1 - Relação Gcal/dam3

\begin{tabular}{lc}
\hline Combustível & Gcal \\
\hline Gás de Alto Forno & 0,780 \\
\hline Gás de Coqueria & 4,000 \\
\hline Óleo BPF & 9,756 \\
\hline Gás Natural & 8,500 \\
\hline
\end{tabular}

Considerando a produção média de vapor nas duas caldeiras que em 2013 foi igual a 57 toneladas por hora temos a seguinte economia de combustíveis:

- Gás de alto forno $=0,128$ dam $^{3} \times 57=7,29$ dam $^{3}$ por hora

- Gás de coqueria = 0,025 dam ${ }^{3} \times 57=1,43$ dam $^{3}$ por hora

- Óleo BPF = 0,010 T x $57=0,57$ T por hora

- Gás natural $=0,012$ dam $^{3} \times 57=0,68$ dam $^{3}$ por hora

A economia acima foi calculada para cada combustível individualmente sendo que ela pode ocorrer de forma individual ou por um mix de combustível que produza 0,10 Gcal de energia.

O cálculo do retorno financeiro foi feito utilizando apenas a economia gerada com o menor consumo de gás de alto forno devido este ser o principal combustível utilizado nas caldeiras.

A economia anual no consumo de Gás de Alto Forno em 2013 foi de:

$7,29 \mathrm{dam}^{3}$ por hora $\times 8760$ horas $=63.860,4 \mathrm{dam}^{3}$

O Gás de Alto Forno economizado pelas caldeiras da CTE\#1 é aproveitado na Central Termoelétrica número 2 (CTE\#2) para produção de energia elétrica.

Transformando o volume de alto forno absorvido pela CTE\#2 em energia térmica e considerando a eficiência da planta que é de 0,32 temos:

$63.860,4 \mathrm{dam}^{3} \times 0,780 \times 0,32=15.939,56 \mathrm{Gcal}$

Convertendo o valor de energia térmica em energia elétrica temos:

$15.939,56 \mathrm{Gcal} /$ 0,86 = 18.534,37 MW

O preço médio da energia produzida pela CTE\#2 em 2013 foi de $\mathrm{R} \$ 82,82$. Logo, o retorno financeiro total em 2013 foi de:

$18.534,37 \mathrm{MW} \times \mathrm{R} \$ 82,82=\mathbf{R} \mathbf{\$} \mathbf{1 . 5 3 5 . 0 1 6 , 5 2}$

A implantação do projeto teve muitos desafios. O principal foi realizar uma substituição completa das malhas de controle e instrumentação de duas caldeiras mantendo suas características de proteção e intertravamento previstas no projeto original. Ouve dificuldades devido às paralisações contratuais que por duas vezes quebraram o ritmo do trabalho. Houve um grande desafio em se realizar a automação de uma caldeira sem causar interferências na caldeira que estava em operação, visto que as paradas dos equipamentos aconteceram em momentos distintos. E por fim, o desafio de entregar a operação um equipamento totalmente reformulado que atendesse as necessidades dos operadores em termos de confiabilidade, segurança, facilidade operacional e ergonomia.

\section{CONCLUSÃO}

O presente trabalho atingiu os objetivos esperados, pois possibilitou novas aplicações tecnológicas em equipamentos antigos, garantindo assim a continuidade operacional dos equipamentos e possibilitando ganhos de performance, confiabilidade, eficiência e segurança.

* Contribuição técnica ao $35^{\circ}$ Seminário de Balanços Energéticos Globais e Utilidades e $29^{\circ}$ Encontro de Produtores e Consumidores de Gases Industriais, 13 a 15 de agosto de 2014, São Paulo, SP, Brasil. 


\section{Agradecimentos}

Agradecemos as pessoas que direta ou indiretamente contribuíram para o desenvolvimento deste trabalho e estão listadas abaixo:

Anderson Lúcio Maia de Andrade - Supervisor de Operação - CSN

Walmor Maurício Totti Machado - Engenheiro de Projetos - CSN

Lucimar Martins Viana - Operador - CSN

Robson Desidério - Operador - CSN

Antônio Carlos da Silva Cabral - Técnico de Instrumentação - CSN

Marcos Aurélio Cardoso - Técnico de Manutenção elétrica - CSN

Ronaldo Lopes Soares Bento - Supervisor de Manutenção - CSN

Fernando Zamboti Fortes - Coordenador de projeto - RV Ciclo

Robson Vitor - Coordenador de projeto - RV Ciclo

\section{REFERÊNCIAS}

1 Egídio Alberto Bega; Instrumentação Aplicada ao Controle de Caldeiras; Terceira edição; Editora Interciência; 2003. 